\title{
EU NÃO ACREDITO QUE TIVE QUE VIR PARA A UNIVERSIDADE PARA CONSTRUIR UM TERRÁRIO!
}

\author{
I don't believe $i$ had to come to university to build a terrary! \\ Eliane Gonçalves dos Santos (eliane.santos@uffs.edu.br) \\ Universidade Federal da Fronteira Sul - UFFS
}

\begin{abstract}
Resumo: Este texto apresenta uma reflexão sobre o desenvolvimento de uma prática investigativa com licenciandos de Ciências Biológicas - Licenciatura. A atividade foi realizada no componente de Laboratório de Ensino, que tem como um de seus objetivos o desenvolvimento e a demonstração de experimentos de Biologia, Física e Química para promover uma cultura investigativa e científica no ensino de Ciências e Biologia. Assim, foi proposto aos acadêmicos da $4^{a}$ fase, a construção de um terrário, mesmo que este não represente de forma fiel um ambiente natural. Porém, a partir desse miniecossistema é possível promover a introdução e discussão de conceitos básicos da Ecologia. Com a escrita deste relato busco apresentar a importância da realização de atividades experimentais na formação inicial de professores, uma vez que são práticas com potencialidades para desenvolver nos sujeitos a capacidade de aprender determinados aspectos da ciência e promover um processo de ensino investigativo e crítico que contribui para a aprendizagem dos alunos.
\end{abstract}

Palavras-chave: Ensino e aprendizagem; Práticas investigativas; Experimentação; formação de professores.

Abstract: This text presents a reflection on the development of an investigative practice with graduates of Biological Sciences - Degree. The activity was carried out in the Teaching Lab component, which has as one of its objectives the development and demonstration of experiments in Biology, Physics and Chemistry to promote an investigative and scientific culture in the teaching of Science and Biology. Thus, it was proposed to the students of the 4th phase, the construction of a terrarium, even if it does not faithfully represent a natural environment. However, from this mini-ecosystem it is possible to promote the introduction and discussion of basic concepts of ecology. With the writing of this report I seek to present the importance of conducting experimental activities in initial teacher education, since they are practices with potential to develop in the subjects the ability to learn certain aspects of science and to promote a process of investigative teaching and critical that contributes for student learning.

Keywords: Teaching and learning; investigative practices; Experimentation Teacher Training. 


\section{Vol. 2, n. 3 - Edição Especial: Ciclos Formativos em Ensino de Ciências.}

\section{INTRODUÇÃO}

Atividades práticas, são temáticas amplamente investigadas e discutidas no Ensino de Ciências, em decorrência das possibilidades que estas podem proporcionar à formação científica dos alunos da Educação Básica e dos futuros professores. Pesquisadores como Galiazzi et al., 2001; Rosito, 2008; Fagundes, 2007; entre outros discorrem sobre as vantagens da realização de atividades, como, os experimentos investigativos no ensino, pois, essas podem favorecer os processos de ensino e de aprendizagem, bem como "o desenvolvimento de habilidades cognitivas nos nossos alunos" (GAIA et al., 2009, p. 9)

Porém, para alcançar tais objetivos com essa prática, não podemos esquecer que é fundamental que o professor tenha uma boa bagagem teórica para conduzir uma aula com investigação, compreendendo a importância de aliar teoria e prática no seu fazer docente. De forma a não perpetuar um entendimento empírico indutivista acerca das atividades experimentais, como nos apresenta Gaia et al. (2009, p. 9-10),

\footnotetext{
[...] Nessas atividades, não raramente, são valorizados principalmente aspectos como a manipulação de materiais e a comprovação de teorias. Os alunos seguem um procedimento já pronto, como uma receita, sem entenderem, muitas vezes, o que estão fazendo. Assim, pode-se transmitir aos alunos uma visão equivocada da ciência, como se fosse uma verdade definitiva, como se a experimentação não fizesse parte da construção dos conhecimentos. A atividade experimental, realizada dessa maneira, parece ser empregada no sentido motivador, no qual se cria um ambiente diferente do de costume, não se valorizando a reflexão sobre os resultados do experimento, e o aluno parece realizá-lo sem saber o porquê e para quê. Realizar um experimento apenas como uma mera atividade física dos alunos, na comprovação de uma teoria, não desenvolve potencialidade cognitiva dos mesmos e muito menos os oportunizam a se posicionarem de forma crítica diante de um problema, seja esse de ordem social ou não.
}

Perante o que foi apresentado, compreendo e partilho do entendimento que devemos desenvolver atividades experimentais que instiguem os alunos a pensar, discutir e refletir (FAGUNDES, 2007) a fim de encontrar caminhos para responder os problemas a eles apresentados, utilizando para isso os conhecimentos aprendidos durante sua formação, aliados a processo de pesquisa, e orientação do professor. Partindo dessa ideia, os experimentos investigativos contribuem para o desenvolvimento de habilidades como analisar, compreender, avaliar, manipular, entre outras, pois um "verdadeiro experimento, 


\section{Vol. 2, n. 3 - Edição Especial: Ciclos Formativos em Ensino de Ciências.}

é aquele que permite ao aluno decidir como proceder nas investigações" (ROSITO, 2008, 199).

Nessa perspectiva, como discorre Gaia et al. (2009, p.11) as "atividades experimentais desenvolvidas a partir de um problema pode ser um instrumento muito poderoso de aprendizagem", para tanto é necessário que os professores tenham conhecimento sobre como proceder para realizar tal atividade, assim como que a experimentação investigativa, esteja presente durante o processo de formação inicial dos professores para que esses possam se familiarizar e se apropriarem dessa modalidade de ensino.

Nesse contexto, relato uma experiência vivenciada com a turma de $4^{\mathrm{a}}$ fase de Ciências Biológicas, na Prática de Ensino IV: Laboratório de Ensino, componente curricular (CCR) que ministro.

\section{PERCURSO METODOLÓGICO}

A atividade aqui descrita faz parte de uma das propostas pedagógicas do componente curricular Prática de Ensino IV: Laboratório de Ensino, do curso de Ciências Biológicas - Licenciatura de uma Instituição Pública de Ensino Superior do Sul do Brasil. Um dos objetivos deste componente é o desenvolvimento e a demonstração de experimentos de Biologia, Física e Química para promover uma cultura investigativa e científica no ensino de Ciências e Biologia. Desta forma, foi proposto aos licenciando da $4^{\mathrm{a}}$ fase do curso do ano de 2018 , a construção de um terrário, para a partir deste promover um processo de investigação e diálogo sobre as possibilidades de trabalho didático com o terrário nas aulas de Ciências e Biologia da Educação Básica, mesmo que o terrário não represente de forma fiel um ambiente natural. Porém, a partir dele é possível promover com os alunos a introdução de conceitos básicos da Ecologia, como: ecossistema, hábitat, nicho ecológico, fatores abióticos e bióticos; temas como fotossíntese e os princípios relacionados a um ciclo de energia, como, as cadeias alimentares e um ciclo de matéria, como, os ciclos biogeoquímicos (ODUM, 1998). Como este componente prima pela 


\section{Vol. 2, n. 3 - Edição Especial: Ciclos Formativos em Ensino de Ciências.}

discussão e reflexão sobre a prática, foi disponibilizado aos acadêmicos um texto sobre a importância das atividades investigativas no ensino de Ciências para dar início as reflexões sobre tal abordagem.

Após leitura e discussão da importância e das potencialidades do desenvolvimento de experimentos investigativo, foi solicitado aos licenciados, que se organizassem em pequenos grupos de 3 a 4 componentes, e trouxessem para a terceira aula do componente, os materiais para a confecção dos terrários: potes de vidros transparente (grandes) com tampa ou garrafas pet (5L), cascalho, areia, carvão, solo (humífero, argiloso), plantas diversas (pequeno porte), galhos secos, minhoca, pequenos animais (insetos), água, algumas ferramentas para o manuseio do solo. A fim de provocar a curiosidade e a busca pelo conhecimento, algumas questões foram feitas aos licenciandos antes que eles começassem a confeccionar os terrários. As questões tinham por objetivo identificar que conhecimentos os futuros professores tinham do assunto, assim, como instigá-los a elaborar hipóteses e a partir da observação deste "mini-ecossistema" refutá-las ou validálas.

Para resguardar o sigilo e anonimato dos sujeitos, serão utilizados códigos para nomear as escritas que foram feitas nos diários de bordo (DB) dos licenciandos durante as aulas de prática (A1, A2, ..., An). Os excertos utilizados serão colocados no texto entre aspas e itálico.

\section{UM OLHAR ATENTO E REFLEXIVO PARA A AULA}

Buscando desenvolver uma atividade investigativa (GAIA et al., 2009; ROSITO, 2008), propus à turma como primeira atividade prática do CCR, a construção de um terrário. Confesso que estava um pouco apreensiva com o desenrolar desta aula, pensando que meus alunos, professores em formação, achariam um pouco "infantil" construir um terrário. Qual foi minha surpresa durante a realização da atividade. Minha sala de aula, com futuros professores parecia uma sala da Educação Básica, alunos agitados, curiosos, com muitos potes, exemplares de plantas e pequenos animais, ansiosos para confecção do "mini-ecossistema". 


\section{Vol. 2, n. 3 - Edição Especial: Ciclos Formativos em Ensino de Ciências.}

Durante a realização da prática, fui percebendo como alguns estavam encantados de fazer tal atividade. Tinham muitas dúvidas, e se questionavam que ao fechar o vidro todas as formas de vida que ali estavam morreriam, como expressou um dos licenciandos "professora, mas, se fecharmos o vidro, as plantas e os animais irão morrer! Como eles conseguiram se alimentar?” (A13, 2018). A partir desta fala e de outras que foram emergindo durante a discussão, percebo que os conteúdos apresentados durante a Educação Básica e mesmo na graduação, não foram significados pelos discentes, pois, alguns acadêmicos têm dificuldade de relacionar os conteúdos científicos com os fenômenos que ocorrem no seu dia a dia.

Assim, aproveitei este momento para indagá-los sobre o que o terrário representava? Que relações e conceitos biológicos poderíamos trabalhar e abordar a partir do terrário? O que esperavam que fosse acontecer ali, naqueles vidros? A interação foi intensa, assim como as dúvidas. Solicitei que anotassem o procedimento, as dúvidas, e as hipóteses que haviam elencado, e pesquisassem sobre o assunto, para que na próxima aula pudéssemos dialogar mais sobre o terrário.

Assim, como Bartzik e Zander (2016, 32-33), entendo que as atividades investigativas possibilitam aos alunos aprenderem a:

formular hipóteses, a experimentar, a observar, a trabalhar em grupo e a tirar conclusões; consequentemente, ele começa a aprender conceitos científicos, relações entre o meio e o ser vivo, a ser mais paciente, responsável e tolerante, denotando assim maior aptidão para o aprendizado.

A realização de atividades experimentais pelo viés investigativo, durante a formação inicial possibilita aos futuros professores a compreensão do desenvolvimento de ações e reflexões centradas na interrelação entre teoria e prática, visando um ensino que instigue o sujeito a pensar e estabelecer conexões entre os conhecimentos científicos e cotidianos, assim, como o desenvolvimento de habilidades investigativas de observação, de manipulação, de argumentação, de comunicação, entre outras.

Desta forma, ao final da aula, enquanto meus futuros professores guardavam os materiais, uma licencianda de maneira espontânea, mas indignada, comenta com os demais colegas "não acredito que tive que vir para a universidade para construir um 


\section{Vol. 2, n. 3 - Edição Especial: Ciclos Formativos em Ensino de Ciências.}

terrário, nunca fiz isso na minha escola" (A27, 2018). Esse foi o ponto alto da aula, diante de tal expressão e das demais colocações que começaram a emergir sobre a realização de experimentações e atividades práticas no ensino, identifiquei que de uma turma de trinta acadêmicos, dois ou três haviam realizado algumas destas atividades na escola, para os demais, a ação era novidade. Tal situação é apresentada por Galiazzi et al. (2001, p. 250),

[...] este é o contexto da pesquisa sobre a experimentação, nossas vivências nas escolas, no entanto, nos mostram que as atividades experimentais são pouco frequentes, embora permaneça a crença dos professores de que, por meio delas, pode se transformar o Ensino de Ciências.

Perante este contexto, apresento o seguinte trecho retirado do DB de uma das licenciandas "confesso que quando nos foi passada a tarefa para a construção do terrário, fiquei um pouco curiosa, pois nunca havia ouvido falar sobre isso, então pesquisei algumas maneiras para montar o nosso" (A3, 2018); neste outro fragmento se observa o encantamento, bem como olhar reflexivo que a estudante faz sobre o momento que está vivenciando “ nosso terrário, terá um novo ecossistema, é tão bonito ver uma criação nossa que nos fará pensar e observar cada mudança” (A19,2018).

A partir dessas duas passagens, entendo que é urgente ampliarmos a discussão, o desenvolvimento de práticas investigativas e experimentais entre outras no ensino de Ciências, durante o processo formativo dos futuros professores, de maneira que essas atividades façam parte de um "discurso tal que professores e alunos possam aprender não só as teorias das Ciências, [...], mas também como se constrói o conhecimento científico em um processo de questionamento", em que a "discussão de argumentos e a validação desses argumentos por meio do diálogo oral e escrito, com uma comunidade argumentativa que começa na sala, mas a transcende" (GALIAZZI; GONÇALVES, 2003, p.331). Só assim, poderemos avançar na qualificação do ensino e na formação dos nossos alunos e professores.

\section{CONSIDERAÇÕES FINAIS}




\section{Vol. 2, n. 3 - Edição Especial: Ciclos Formativos em Ensino de Ciências.}

Com a escrita deste relato busco apresentar a importância do desenvolvimento das atividades de experimentação na Educação Básica, mas não atividades com enfoque reproducionista e demonstrativo, em que os alunos são sujeitos passivos, que não interagem e refletem sobre o que estão realizando. Práticas e debates sobre o papel da experimentação no Ensino de Ciências devem ser introduzidos na formação inicial e continuada dos professores, necessitando serem refletidos a partir de referenciais teóricos que proporcionem uma compreensão de que a experimentação e atividades investigativas são instrumentos com potencialidades para desenvolver nos sujeitos a capacidade de aprender determinados aspectos da ciência, além do que, a experimentação visa na Educação Básica inserir os alunos no contexto do desenvolvimento do pensamento crítico e autônomo.

Ao propor a confecção do terrário com os licenciandos, busquei uma forma de instigá-los a pensar quais conteúdo das Ciências estavam envolvidos na simulação do "mini-ecossistema" que eles haviam construído e as relações conceituais que eles conseguiam estabelecer a partir das discussões e reflexões que fizeram nos grupos. Durante esse processo fui apontando que o terrário é apenas uma possibilidade para ensinarmos, e que devemos ter cuidado ao trabalhar com ele na sala de aula, pois há questões importantes a serem apontadas com os alunos quando se constrói um terrário, como já dito ele "imita" um ecossistema, mas há limitações nesse modelo como: a desconsideração ao habitat das espécies, o desrespeito a questão do nicho ecológico, o comportamento do animal se altera quando este é retirado do seu meio natural, o terrário é um sistema fechado, enquanto na natureza o sistema é aberto e livre, etc. Porém, ao se trabalhar com um terrário em sala de aula, o ideal seria que o professor conduzisse a discussão para que os alunos cheguem nesse entendimento, a partir de leituras, pesquisas, observações e diálogos coletivos, pois é na mediação e na interação com os demais que vamos nos apropriando do conhecimento e aprendendo.

Essa é uma prática que venho realizando nos últimos anos no CCR, já pensei em não fazer mais tal atividade com os licenciandos, mas, a cada ano que ministro o componente e questiono sobre quem já fez um terrário na escola, mais de $80 \%$ dos meus alunos respondem não ter feito, e relatam que aulas experimentais dificilmente eram 


\section{Vol. 2, n. 3 - Edição Especial: Ciclos Formativos em Ensino de Ciências.}

realizadas nas escolas. Ao indagá-los se querem confeccionar o terrário, são unânimes em dizer que sim. O mais incrível deste processo, é que quando estão nos grupos, discutindo sobre como irão proceder na montagem do terrário e sobre deixá-lo aberto ou não, nessa hora muitas perguntas e hipóteses são elencadas e os olhos dos futuros professores brilham, e nossa sala/ laboratório de ensino se transforma. Nesse momento de interação e aprendizagem, parafraseando Chaves (2013) tanto eles quanto eu, vamos no (re)encontrando e encantando com a docência, e compreendendo o papel da experimentação e das atividades investigativa na sala de aula e nos processos de ensino e de aprendizagem.

\section{REFERÊNCIAS}

BARTZIK, F.; ZANDER, L. D. A importância das aulas práticas de Ciências no Ensino Fundamental. Revista @ rquivo Brasileiro de Educação, Belo Horizonte, v.4, n. 8, maiago, 2016.

CHAVES, S. N. Reencantar a ciência, reinventar a docência. São Paulo: Livraria da Física, 2013.

GALIAZZI, M. C.; GONÇALVES, F. P. A natureza pedagógica de experimentação: uma pesquisa na licenciatura em química. Química Nova na Escola, v. 27, n 2, 2004. p. 326331.

FAGUNDES, S. M. K. Experimentação nas Aulas de Ciências: Um Meio para a Formação da Autonomia? In: GALIAZZI, M. C. et al. Construção Curricular em Rede na Educação em Ciências: Uma Aposta de Pesquisa na Sala de Aula. Ijui: Unijui, 2007.

GAIA, A. M. et al. Atividades experimentais de química no Ensino Médio: reflexões e propostas. São Paulo, 2009. Disponível em: $<$ https://ensinointegral.webnode.com/_files/200000194b094fb1916/LIVRO\%20DE\%20ATIVIDADES\%20EXPERIMENTAIS\%20INVESTI GATIVAS.pdf.> Acesso em 16 de jun.2015

GALIAZZI, Maria do Carmo et al. Objetivos das atividades experimentais no Ensino Médio: a pesquisa coletiva como modo de formação de professores de Ciências. Ciência e Educação, Bauru, v. 7, n. 2, p. 249-263, 2001. Disponível em: < http://www.scielo.br/pdf/ciedu/v7n2/08.pdf>. Acesso em 02 jul. 2015.

ODUM, E. Ecologia. Rio de Janeiro: Guanabara Koogan, 1998.

ROSITO, Berenice Alvares. O ensino de Ciências e a experimentação. In: MORAES, Roque (Org.). Construtivismo e ensino de Ciências: reflexões epistemológicas. 3. ed. Porto Alegre: EDIPUCRS, 2008. p. 195-208. 